\title{
Preliminary Studies on Glycine Max Ethanol Extract (GMEE)
}

Deepa Gopinath*

IAPMO Plumbing Codes and Standards India Pvt. Ltd., Bangalore-560100, India.

Senior Scientist, Microbiological Research and Developmental Lab, Bangalore-560100, India.

E-mail: deepa.microfamily@gmail.com*

DOI: http://doi.org/10.38177/ajast.2021.5315

Copyright: () 2021 Deepa Gopinath. This is an open access article distributed under the terms of the Creative Commons Attribution License, which permits unrestricted use, distribution, and reproduction in any medium, provided the original author and source are credited.

\section{ABSTRACT}

Present study deals with the preliminary study of Glycine Max Ethanol Extract (GMEE). GMEE stacks more macro and micro nutrients with many pharmacological and nutraceutical standards. GMEE was preliminary screened by simple test methods and instrumentation methods such as RP-HPLC, IR and GC-MS. The obtained results from IR predicted the presence of different functional groups such as $\mathrm{OH}, \mathrm{CH}_{2}, \mathrm{C}=\mathrm{O}, \mathrm{C}-\mathrm{O}$ and cyclic ring. While, the RP-HPLC and GC-MS profiles of GMEE predicted the presence of lipids, polyphenols, alkaloids and flavonoids in the extract.

Keywords: Glycine Max Ethanol Extract (GMEE), GC-MS, RP-HPLC and IR.

\section{Introduction}

Glycine Max is very rich in several beneficial phytoconstituents [1], it is one of the most common crop cultivated in European countries due to its wide range of pharmacological and nutraceutical properties [2]. Glycine max is also commonly called as soybean and it falls under legumes family [3]. The great value of glycine max in health sector industries, increases the value of its consumers day by day [4]. Especially is Asian continent the vegetable soy bean is well established legume in human diet [5]. Genistein, biochanin and daidzein are the major biological active iso-flavonoids are present in the glycine max [6].

Moreover, due to its increase in the popularity of glycine max as a nutraceutical product, USA importing soy bean 25000 tones every year [7]. Regular consumption of soybean reduces the risks factors associated with various cancers such as prostate, mammary and many other chronic inflammatory diseases [8]. Furthermore, iso-flavonoids present in the glycine max reported that it increase the level of HDL and lower the level of LDL cholesterol [9]. Numerous phytochemicals are present in the glycine max which may exert many pharmacological and nutraceutical properties which may be still unknown [10]. Thus, to evolve the unknown phytochemicals present in the glycerin max this preliminary study of glycine max ethanol extract was carried out as described further below in this manuscript. I believe this research study may help in one in another way to new emerging bud researcher to evaluate the unknown phytochemicals from glycine max.

\section{Materials and Methods}

All the chemicals used were of analytical grade.

\section{Glycine Max Ethanol Extract (GMEE) preparation}

Glycine max were purchased from local market of Bangalore. From the glycine max, GMEE was extracted by the solvent ethanol using Soxhlet extraction method. The finally obtained extract was termed as GMEE (Glycine Max Ethanol Extract) and it utilized for further assays. 


\section{Karl fisher titration method}

Moisture content of GMEE was identified by Karl fisher (Kf) titration method.

Briefly, $10 \mathrm{~mL}$ of GMEE (in conical flask) was titrated against $\mathrm{Kf}$ reagent containing free iodine using $\mathrm{Kf}$ instrument (light brown end point) and note down the burette reading.

Calculation: \% of moisture $=\frac{\text { Burette reading } \times 5.8 \mathrm{Kf} \text { value }}{\text { Weight of sample }} \times 100$

\section{Residue on ignition}

To quantify the amount of inorganic metal ions in the extract, $1 \mathrm{~g}$ of GMEE was added to pre-weighed crucible and weight was recorded. Then it was kept in muffle furnace at $350^{\circ} \mathrm{C}$ for $2 \mathrm{hr}$. After the incubation period crucible was again weighed and record the weight.

Calculation: $\frac{W_{3}-W_{1}}{W_{2}-W_{1}} \times 100$

Where,

$\mathbf{W}_{1^{-}}$Weight of empty crucible

$\mathbf{W}_{2}$-Weight of GMEE + crucible (before incubation time)

$\mathbf{W}_{3}$-Weight of GMEE + crucible (after incubation time)

\section{Test for Carbohydrates}

GMEE $(100 \mu \mathrm{g})$ was mixed with few drops of Benedict's solution and boiled in water bath. Observed for reddish brown precipitation.

\section{Test for Proteins}

GMEE (100 $\mu$ g) was treated with $10 \% \mathrm{NaoH}$ solution and add 2 drops of $0.1 \% \mathrm{CuSO}_{4}$ solution. Observed for violet pink color.

\section{Test for Lipids}

GMEE $(100 \mu \mathrm{g})$ was treated with $0.5 \mathrm{~N}$ alcoholic $\mathrm{KoH}$ and add 1 drop of phenolphthalein as indicator. This solution was heated in water bath for $1 \mathrm{hr}$. Observed for white color foam.

\section{Test for Alkaloids}

GMEE $(100 \mu \mathrm{g})$ was treated with few drops of Hager's reagent saturated picric acid solution. Observed for yellow precipitation

\section{Test for tannins}

GMEE $(100 \mu \mathrm{g})$ was treated with gelatin solution. Observed for white precipitation. 


\section{Test for steroids}

GMEE $(100 \mu \mathrm{g})$ was mixed with few-drops of acidic anhydride boiled and cooled. Then concentrated sulphuric acid was added by sides of the test tubes.

Observed the formation of brown ring at the junctions of two layers.

\section{Test for Flavonoids}

GMEE $(100 \mu \mathrm{g})$ was treated with sulphuric acid and observed for the formation of orange color.

\section{Phenol test}

GMEE $(100 \mu \mathrm{g})$ was treated with 5\% ferric chloride and observed for the formation of deep blue or black color.

\section{Glycosides Test}

GMEE $(100 \mu \mathrm{g})$ was hydrolyzed with concentrated HCL for $2 \mathrm{hr}$ on a water bath and filtered. Few $\mathrm{mL}$ of above filtrate was shaken with chloroform and add 10\% of ammonia. Formation of pink color indicated the presence of glycosides.

\section{IR spectrum}

Fourier Transform Infrared (FT-IR) spectrum was recorded on Agilent FT-IR-4100 spectrophotometer in the spectral range of $650-4000 \mathrm{~cm}^{-1}$ taking the sample in the form of ATR powder discs (Baker S et al., 2012)

\section{Reverse Phase High Performance Liquid Chromatography analysis}

GMEE $(10 \mu \mathrm{g})$ was subjected to RP-HPLC using $\mathrm{C}_{18}$ column $(150 \mathrm{~mm} \times 4.60 \mathrm{~mm}$, particle size $5 \mu \mathrm{m})$ with PDA detector in shimadzu LC-20AD prominence. The column was pre-equilibrated with $0.1 \%$ Trifluoroacetic acid (TFA) in water and it was eluted at the flow rate of $1 \mathrm{ml} / \mathrm{min}$ in linear gradient mode.

\section{$G C-M S$}

GC-MS analysis of samples was analyzed on quadrupole mass spectrometers in the Electron Capture Negative Ion Chemical Ionization (ECNICI) mode with capillary column (30X0.25mm IDX1EM df, composed of 100\% Dimethyl poly siloxane).

Helium (99.9\%) gas was used as carrier gas at the flow rate of $1 \mathrm{ml} / \mathrm{min}$ and the injection volume of $0.5 \mathrm{El}$ (split ratio of 10:1). Temperature program was set as follows, injector temperature $250^{\circ} \mathrm{C}$; ion-illuminator temperature $280^{\circ} \mathrm{C}$, oven temperature $110^{\circ} \mathrm{C}$ (isothermal for $3 \mathrm{~min}$ ) with an increase in temperature of $20^{\circ} \mathrm{C} / \mathrm{min}$ to $220^{\circ} \mathrm{C}$, thereafter $5^{\circ} \mathrm{C} / \mathrm{min}$ to $300^{\circ} \mathrm{C}$. Mass spectrum was taken at $80 \mathrm{ev}$; a scan interval of $0.5 \mathrm{~s}$ [8].

\section{Results and Discussion}

\section{Physical and chemical Characterization of GMEE}

The extracted GMEE was look like fairly gray color and pungent odor. To know the chemical composition of GMEE, simple test tube chemical analysis was done. Interestingly, GMEE shows positive response for lipid, alkaloid, phenols and flavonoid tests with trace amount of inorganic metal ions and $10 \%$ of moisture content. 


\section{AJAST}

Asian Journal of Applied Science and Technology (AJAST)

Volume 5, Issue 3, Pages 156-161, July-September 2021

\section{Fourier Transform Infrared (FT-IR) spectroscopy}

The IR spectrum of GMEE confirms that presence of stretching vibrational band for $\mathrm{OH}$ group, aromatic $\mathrm{C}-\mathrm{H}$ group, coordinated carbonyl $(\mathrm{C}=\mathrm{O})$ stretching of $\mathrm{CHO}$ group and the bending form $\mathrm{C}-\mathrm{H}$ aliphatic groups.

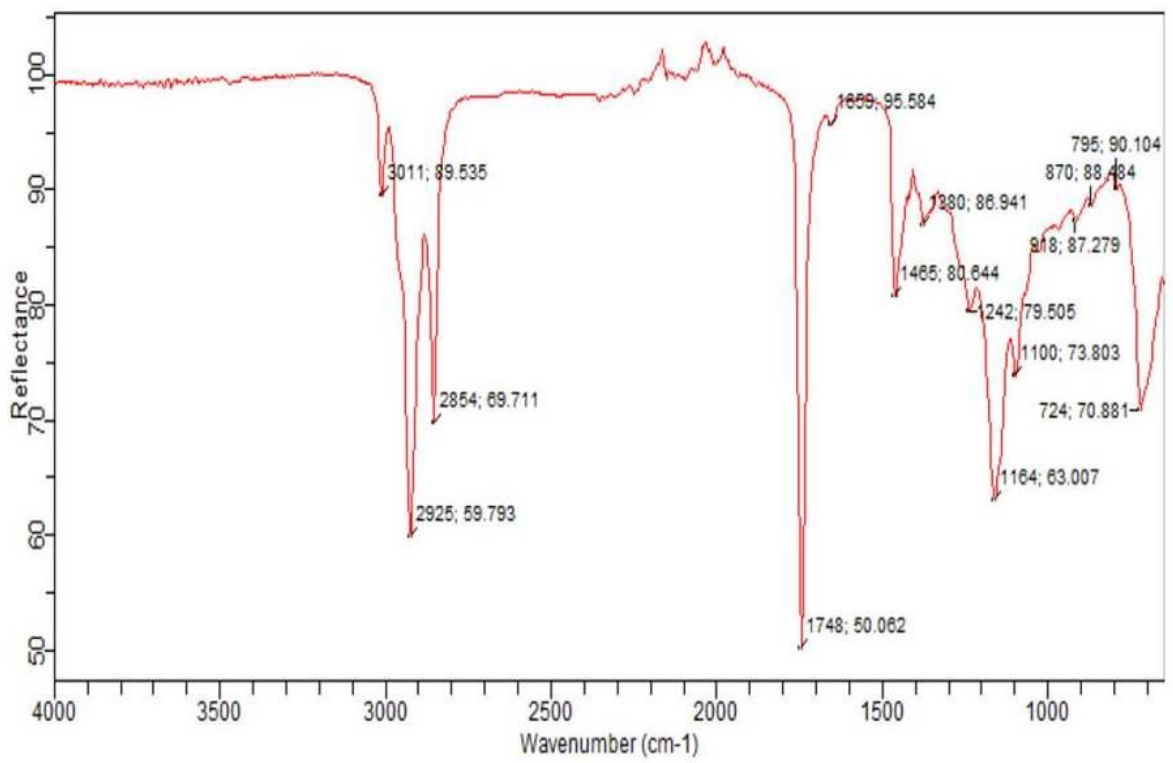

Fig.1. FT-IR Spectra of GMEE

\section{$R P-H P L C$}

Further the presence of phytochemicals (Alkaloids, flavonoids, lipids and phenolic compounds) in GMEE was confirmed by RP-HPLC chromatogram. GMEE $(10 \mu \mathrm{g})$ was injected to $\mathrm{C}_{18}$ Column $(5 \mathrm{~mm}, 0.21 \mathrm{X} 25 \mathrm{~cm})$ which was pre-equilibrated with $0.1 \%$ Tri-Fluoro Acetic Acid (TFA) in water and sample was eluted in gradient mode by increasing the concentration (0-100\%) of $0.1 \%$ TFA in acetonitrile for $20 \mathrm{~min}$ at the flow rate of $1 \mathrm{~mL} / \mathrm{min}$ and monitored at $280 \mathrm{~nm}$.

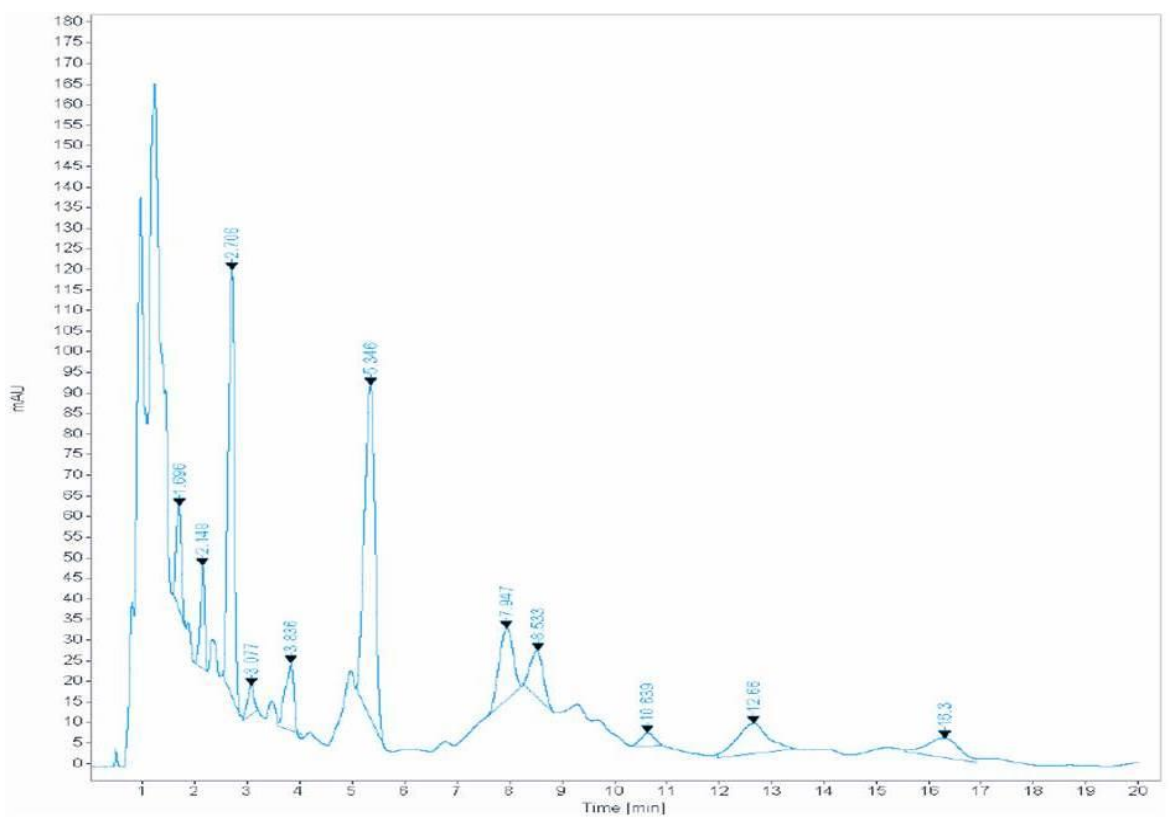

Fig.2. RP-HPLC chromatogram 


\section{AJAST}

Asian Journal of Applied Science and Technology (AJAST)

Volume 5, Issue 3, Pages 156-161, July-September 2021

\section{Quantification by $G C-M S$}

Moreover, the presence of phytochemicals (Alkaloids, flavonoids, lipids and phenolic compounds) in GMEE was also adjudged by GC-MS chromatography technique. Interestingly, as like RP-HPLC chromatogram in GC-MS also 11 major peaks were obtained (Fig.03).

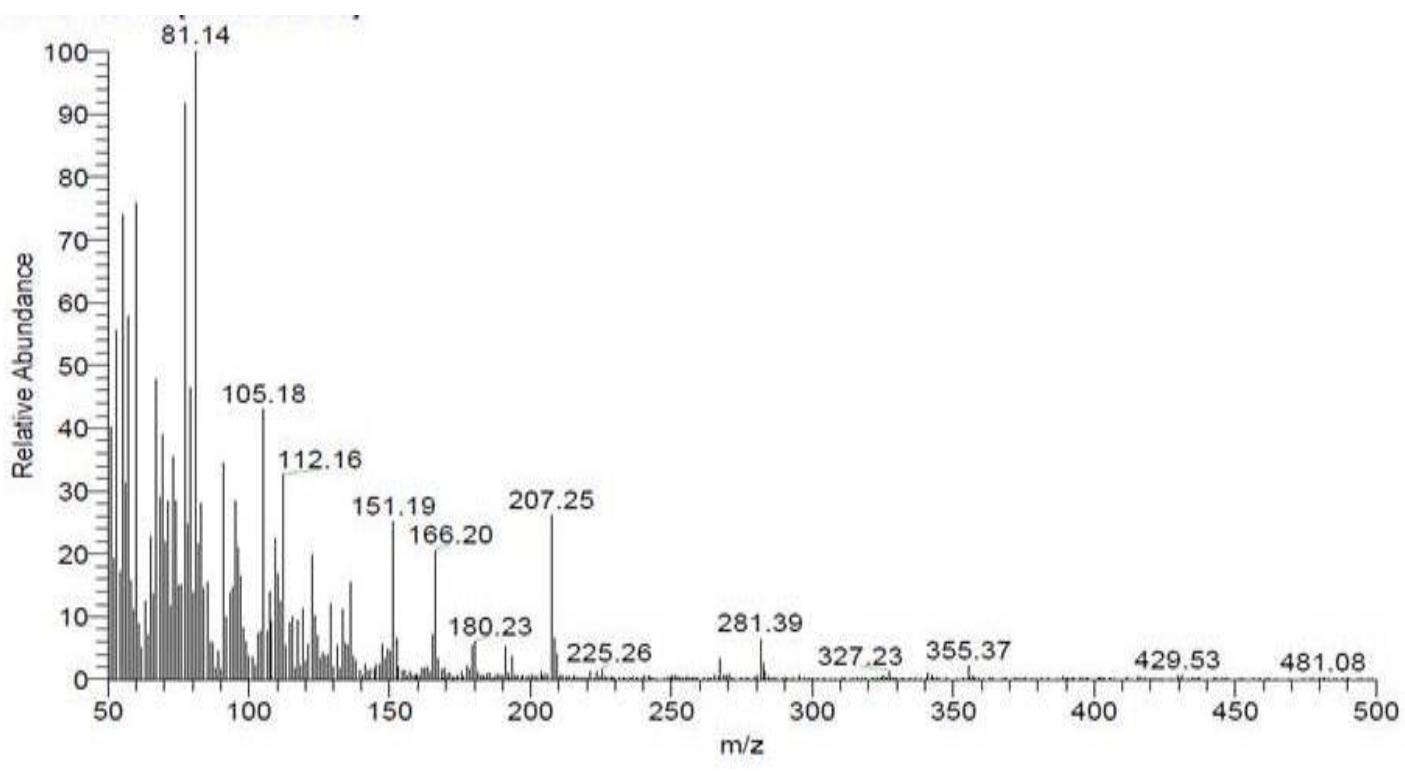

Fig.3. GC-MS Chromatogram of GMEE

\section{Conclusion}

In conclusion, this study demonstrates the characterization of GMEE. Thus, isolation and purification of active compound sounds to be good.

\section{Acknowledgments}

Deepa Gopinath thanks Aqua diagnostic research center for their support in the research work.

\section{Declarations}

\section{Source of Funding}

This research did not receive any grant from funding agencies in the public, commercial, or not-for-profit sectors.

\section{Competing Interests Statement}

The author declares no potential conflict of interest with respect to the authorship and publication.

\section{Consent for publication}

Author declares that he/she consented for the publication of this research work.

\section{References}

[1] Abe T, Kano M \& Sasahara T, (2005), Quantitative difference of 7s globulin on vegetable soybean seeds, Journal of the Japanese Society for Food Science and Technology, 52: 107-113. 
[2] Ahmed N S \& Helal F R, (1977), The infrared absorption spectra for measuring the unsaturation in milk fat and oils, Milchwissenscaft, 32: 272-273.

[3] Al- Wahsh I A, Horner H T, Palmer G, Reddy M B \& Massey L K, (2005), Oxalate and phytate of soy foods, Journal of Agricultural and Food Chemistry, 53: 5670-5674.

[4] Andi O C, Tz SG, Been L \& Yung S C, (1995), Effects of Precooling and fresh storage conditions on the qualities of fresh frozen vegetable soybeans, Food Science, 1: 12-26.

[5] Beckmann K B \& Ames V N, (1997), Oxidative decay of DNA, J. of Biological Chemistry, 272: 19633-19636.

[6] Boveris A, Cadenas E \& Stoppans A O M, (1976), Role of ubiquinone in the mitochondrial generation of hydrogen peroxide, Journal of Biochemistry, 156: 435-444.

[7] Boveris A, Oshino N \& Chance B, (1972), The cellular production of hydrogen peroxide, Journal of Biochemistry, 128: 617-630.

[8] Justesen U, Knuthsen P \& Leth T, (1998), Quantitative analysis of flavonols, flavones, and flavanones in fruits, vegetables and beverages by high-performance liquid chromatography with photo-diode array and mass spectrometric detection, Journal of Chromatography A, 799: 101-110.

[9] Carter T E \& Shanmugasundaram S, (1993), Edamame, the vegetable soybean, In underutilized crop: pulses and vegetable (T. Howard, Ed.), 6: 219-239.

[10] Demirbuker M \& Blomberg, LG, (1990), Group separation of triacyl glycerols on micropacked argentation columns using supercritical media as mobile phase, Journal of Chromatographic Science, 28: 67-72. 